\title{
JORNAL ESCOLAR: GÊNERO E DISCURSO NO ENSINO FUNDAMENTAL¹
}

\author{
SCHOOL NEWSPAPER: GENRE AND DISCOURSE AT ELEMENTARY SCHOOL
}

\author{
Vanessa Wendhausen Lima ${ }^{1}$ \\ ${ }^{1}$ Faculdade SATC - Educação e Tecnologia (SATC), Criciúma, SC, Brasil. \\ vanessa.wendhausen@satc.edu.br
}

Recebido em 21 set. 2018

Aceito em 11 out. 2018

Resumo: O objetivo deste trabalho é analisar, do ponto de vista da Análise Crítica de Gênero (BONINI, 2011), a relação entre gênero e prática social em jornal escolar produzido por alunos de uma turma de correção de fluxo dos anos finais do ensino fundamental de uma escola pública estadual do município de Tubarão, SC. Esta pesquisa é um excerto de um projeto de letramento aplicado em virtude da tese de doutorado da autora e o objeto produzido, um jornal escolar, pretendia favorecer e/ou estimular o compromisso do aluno com sua própria aprendizagem. Tendo em vista a influência da prática social na produção de gênero, este artigo demonstra que um gênero produzido em sala de aula sofre a ação das crenças, histórias, valores e identidades dos indivíduos produtores. Os resultados sugerem, de um lado, que a prática social influencia a produção do gênero jornal escolar e não pode ser excluída do processo de análise genérica; e, de outro, considerando que o gênero é uma materialização discursiva, através do trabalho com gêneros na escola é possível atingir e provocar transformações na dinâmica de funcionamento social dos discursos. O jornal escolar visto como um gênero, demonstra que a escola deve se posicionar para além do estabelecimento de regras de ensino e entender que as influências extraescolares podem estar bem mais presentes do que se previa.

Palavras-chave: Jornal Escolar. Prática Social. Análise Crítica do Gênero.

Abstract: The objective of this study is to analyze, from the point of view of the Critical Gender Analysis (BONINI, 2011), the relationship between gender and social practice in a school newspaper produced by students of an elementary school class state public school in the municipality of Tubarão, SC. This research is an excerpt from a literacy project applied by the author's doctoral thesis and the object produced, a school newspaper, intended to favor and/or stimulate the student's commitment to his own learning. Considering the influence of social practice on gender production, this article demonstrates that a class produced in the classroom is influenced by the beliefs, histories, values and identities of the individuals who produce them. The results suggest, on the one hand, that social practice influences the production of the school newspaper genre and cannot be excluded from the generic analysis process; and, on the other, considering that gender is a discursive materialization, through work with genres at school it is possible to reach and provoke transformation in the dynamics of social functioning of discourses. The school newspaper, seen as a genre, demonstrates that the school must position itself beyond the establishment of rules of teaching and understand that extracurricular influences may be far more present than anticipated.

Keywords: School Newspaper. Social Practice. Genre Critical Analysis.

\section{Introdução}

Desenvolver a escrita em ambiente escolar tem se mostrado uma tarefa mais árdua tanto para professores quanto para alunos. Isso tem acontecido não só pela

\footnotetext{
${ }^{1}$ Este trabalho é um excerto da tese de doutorado da autora, que foi orientada pelo professor doutor Adair Bonini, na Universidade do Sul de Santa Catarina, em convênio com a Universidade Federal de Santa Catarina.
} 
forma como as novas gerações tem lidado com seu próprio aprendizado ou com o gerenciamento do alto fluxo de informação com o qual convivem, mas também por entenderem que os métodos de ensino já não se mostram eficientes em comparação com o acesso fácil ao banco de dados da internet.

No entanto, todo o acesso à informação não será suficiente se o indivíduo não souber como administrá-lo. É relevante refletir sobre essa dinâmica, tendo em vista o funcionamento da escrita, que não se refere apenas aos aspectos do "saber ler e escrever" e que está mais para o domínio do funcionamento da linguagem como um todo, um dispositivo social que produz sentido mediante as atividades dos sujeitos e que se modifica e influencia os aspectos da vida social. Contudo, é preciso entender que linguagem "em movimento" é discurso e uma das formas de manifestações discursivas é o gênero.

O gênero sofre influências diversas, entre elas, a exercida pelo discurso que, por sua vez, pode ser considerado um dos momentos da prática social, que movimenta e regula o funcionamento da sociedade. O contexto de produção de um gênero não pode ser suficientemente analisado e/ou entendido se a análise estiver limitada ao textual. Para dar conta de uma análise genérica desse nível, é preciso considerar as relações dialógicas que envolvem o gênero e, sobretudo, quais os aspectos dessas relações influenciam e se manifestam em sua produção.

A partir disso, uma análise crítica de gênero deve ir além do textual, tomando como central a relação entre o gênero e a prática social. Essa relação é um dos aspectos centrais do quadro teórico-metodológico da Análise Crítica de Gênero (BONINI, 2011), que fundamenta essa pesquisa e evidencia a necessidade de uma visão crítica perante a relação linguagem-sociedade, assumindo uma perspectiva de "crítica" discursiva e se utilizando de pressupostos pertencentes ao quadro teórico da Análise Crítica do Discurso, de Fairclough (2008/1992, 2003) e de alguns aspectos do enunciado e dos Gêneros do Discurso, de Bakhtin (2004/1979, 2011/1953).

Esta pesquisa toma o gênero jornal escolar como objeto de ensino e de análise, incentivando o protagonismo escolar, abrindo espaço para a autoria 
discente e para a educação crítica. Produzido por uma turma de correção de fluxo² dos anos finais do ensino fundamental de uma escola pública estadual do município de Tubarão, SC, este jornal escolar se configura como um projeto de letramento.

\section{Análise crítica do gênero}

De acordo com Lima (2014), é possível perceber que a Análise Crítica do Gênero, de acordo com o proposto por Bonini (2011), apresenta-se como um quadro teórico-metodológico que busca entender a dinâmica de funcionamento dos gêneros. Isso significa pensar, também, naquilo que influencia os gêneros que circulam socialmente, quais práticas sociais podem impulsionar seu surgimento ou apagamento e de que forma os discursos se fazem presentes na constituição genérica.

Gêneros não surgem do vazio, mas sempre de uma relação de interação com outros gêneros e com outros aspectos do contexto que os abrigam. Responsáveis por organizar a comunicação humana, o funcionamento dos gêneros depende tanto de outros gêneros, quanto das estruturas que regulam sua circulação e, por consequência, da forma como os sujeitos estabelecem contato com aqueles. Os sujeitos, por sua vez, só têm a possibilidade de conhecer e de dominar a utilização dos gêneros, porque estes contam com suportes físicos e sociais que permitem sua existência e sua circulação social.

Segundo Bonini (2011), os gêneros se constituem através de relações dialógicas e interdependentes estabelecidas com outros gêneros, com as práticas sociais e discursivas, com as estruturas sociais e com o discurso. Essas relações podem estar restritas ao campo do enunciado ou ampliadas ao âmbito do discurso e das estruturas sociais.

Os sujeitos produtores/receptores envolvidos com o gênero estão envolvidos também em uma série de ações que podem ser relativas às ações de produção, ações de compreensão e ações de textualização, ou seja, aquelas habilidades que os sujeitos produtores/receptores precisam acionar quando chamados à produção,

\footnotetext{
2 Por turmas de correção de fluxo denominam-se projetos das secretarias estaduais de educação que têm por objetivo corrigir a disparidade idade/série de alunos matriculados nos anos finais do ensino fundamental. Essas turmas costumam reunir estudantes que apresentaram histórico de reprovações e, por isso, apresentam também uma idade superior aos colegas de turmas regulares.
} 
textualização e compreensão de um gênero, por exemplo: os conhecimentos sobre o gênero e seus objetivos; o conhecimento de mundo necessário para a textualização ou a identificação do público receptor e do que ele espera compreender desse gênero. Essas ações provocam um resultado a que se pode chamar de prática social do gênero.

O gênero está imerso em práticas sociais que lhe são inerentes e que determinam sua forma, seu conteúdo, a maneira como os sujeitos o (re)produzem e o compreendem. Essa relação dialógica é um fator constitutivo do gênero, evidenciando sua conexão a outro gênero, assim como uma prática discursiva está sempre ligada à outra, interferindo-se e influenciando-se mutuamente.

Essa relação de constituição é essencial, pois, em alguns casos, os gêneros nem existiriam se não fossem alguns elementos (o suporte e a mídia, por exemplo), isto é, sem estes, os gêneros não poderiam circular ou seriam completos desconhecidos dos sujeitos. Essa relação de interação entre os gêneros e esses elementos, segundo Bonini (2011), pode ser chamada de relação genérica e podem ocorrer de quatro formas: com o hipergênero, com a mídia, com o sistema de gêneros e com a comunidade discursiva.

O gênero pode se relacionar com um hipergênero, uma espécie de agrupamento de gêneros, onde as produções genéricas simplesmente acontecem em conjunto. Conforme Bonini (2011, p. 691), essa produção pode ocorrer num agrupamento, que permite formar "uma unidade de interação maior (um grande enunciado)", como o jornal, por exemplo. A mídia, por sua vez, é uma "forma tecnológica material de mediação da interação linguageira, sendo que ela constituise de um ou mais suportes e apresenta uma forma característica de organização, produção e recepção" (BONINI, 2011, p. 693). A relação com a mídia é essencial, tendo em vista que, segundo o autor, é a mídia que põe o gênero em circulação e, ainda, organiza os sujeitos produtores/receptores através do cenário espaçotemporal dos gêneros. Ainda segundo o autor, "gêneros e hipergêneros se ajustam às formas de produção e recepção possibilitadas pela mídia". Os gêneros, com suas práticas discursivas, tanto quanto os sujeitos que os produzem/recebem, precisam se ajustar às possibilidades midiáticas para que possam entrar e se manter em circulação social. Por isso, esta é outra das relações que constituem e, de alguma forma, determinam o gênero. 
Quanto ao sistema de gêneros, conceito proposto por Bazerman (2006), Bonini (2011, p. 693) declara que "os gêneros podem ser vistos como elementos de uma sequência de práticas e ações sociais [...] [em que] um gênero cria condições para existência de outro". Já no que se refere à comunidade discursiva, conceito proposto por Swales (1990), "os gêneros em uma comunidade discursiva, estão a serviço de uma hierarquia de membros que, juntos, realizam um conjunto de práticas sociais também hierarquizadas" (BONINI, 2011, p. 693).

Outro possível nível de análise, conseguinte às relações genéricas, refere-se às relações do plano do discurso. Para o autor, gêneros são materializações do discurso, assim como as práticas sociais imersas nos gêneros também influenciam os discursos. Por último, aparecem as relações no plano da estrutura social. "As instituições (como a igreja, a economia e a ciência) constituem tanto os discursos quanto as práticas sociais e são, ao mesmo tempo, por esses constituídas" (BONINI, 2011, p. 694).

Segundo Bonini, seu quadro conceitual permite, quando observado numa perspectiva ascendente, a possibilidade de uma análise que parta do gênero rumo ao discurso, construindo uma análise crítica de gêneros. O contrário também é possível: numa perspectiva descendente, permite construir um caminho para a análise crítica do discurso. Ao se optar pela análise crítica de gêneros como fundamento teórico-metodológico para este trabalho, entende-se a necessidade de traçar uma rota possível que vá além do textualmente explícito e busque identificar e refletir sobre as assimetrias de poder que influenciam a constituição dos gêneros e dos discursos.

\section{0 gênero jornal escolar}

Há três possibilidades de definição para o jornal: como um suporte textual, como uma mídia (devido ao seu status social adquirido) ou como um gênero. Para se definir o jornal como um gênero (pensamento assumido neste trabalho) é preciso elencar os aspectos em que se baseia essa caracterização. De acordo com Bonini (2008, p. 35) "há motivos para se considerar o jornal um gênero [...] porque [este] preenche quesitos como propósitos comunicativos próprios, organização textual característica e produtores e receptores definidos". Partindo desse pensamento, 
classifica-se o jornal escolar como um gênero por encontrar nas edições analisadas algumas das características elencadas.

O propósito comunicativo do jornal escolar é um dos itens que permitem fomentar regularidades que o caracterizem como gênero. Num jornal convencional, basicamente, seu propósito comunicativo está relacionado, conforme Bonini (2001), às ações de noticiar, opinar, criticar. Esse propósito pode ser tomado como um dos aspectos que permite a identificação de um jornal como tal. É preciso ressaltar que a utilização do conceito "propósito comunicativo" vem de Bonini $(2001,2008)$ e, assim como o autor não utiliza esse conceito em seus trabalhos mais recentes, este trabalho também não pretende fazer referência aos estudos da área que veem o gênero como realizador de um propósito comunicativo apenas.

No que se refere ao jornal escolar, opta-se por pensar em "objetivo" do gênero jornal escolar que é, além de se configurar como um instrumento de ensino e de aprendizagem, promover a interação discente e incentivar os estudantes a assumirem uma posição mais central em seu processo de aprendizagem escolar. Em essência, o objetivo desse gênero, apesar de algumas vezes parecer se perder ao longo da produção, é incentivar a prática de escrita autoral pelos estudantes. No entanto, não é difícil destacar que o jornal escolar possa assumir alguns aspectos que contemplam os mesmos propósitos comunicativos do jornal convencional, como noticiar, criticar ou opinar, entretanto, um objetivo ideal para o jornal escolar é dar prioridade à interação discente, a fim de evitar que a produção se torne escolarizada.

Além do propósito comunicativo, um jornal pode ser considerado um gênero por apresentar uma organização textual característica que pode ser encontrada em diversos exemplares de jornal (escolares ou convencionais). Esta organização pode ser marcada pela presença de itens como o cabeçalho, a chamada, a manchete e/ou a fotografia. Esses itens dispostos e agrupados num conjunto de páginas que formam uma unidade costumam levar a uma identificação no público consumidor: trata-se de um jornal. Tem sido possível perceber que essas características podem ser estendidas ao jornal escolar, tendo em vista que este último ainda busca se legitimar como jornal escolar, ao assumir características comuns ao jornal convencional. 
Outro aspecto que permite que o jornal seja pensado como um gênero é o fato de que este serve como um agregador de outros gêneros. É um aspecto que, além de definir sua organização característica, o estabelece como um jornal, pois este não seria um jornal se não trouxesse notícias ou reportagens, se não apresentasse um cabeçalho ou um expediente, se não tivesse um caderno (de algum tema específico, como o de esportes ou o de classificados) ou a seção de carta do leitor. A presença recorrente desses gêneros faz do jornal um hipergênero, isto é, um gênero que abriga outros gêneros. Esses gêneros agrupados, assim como outros itens presentes no jornal, tais como os aparatos de edição, são os responsáveis por fornecer uma organização textual característica e, por isso, permitem sua identificação não apenas como um jornal, mas como um hipergênero. No quadro a seguir, é possível ver os gêneros e aparatos elencados por Bonini (2008) como elementos frequentes no jornal.

Figura 1 - Gêneros e aparatos de edição do jornal

\begin{tabular}{|l|l|ll|}
\hline \multicolumn{2}{|l|}{ Gêneros } & \multicolumn{2}{l|}{ Aparatos de Edição } \\
\hline Presos: & Livres: & Manchete & Exemplo \\
Editorial & Notícia & Lide & Selo \\
Carta do leitor & Nota & Lista & \\
Expediente & Crítica & Painel & \\
Chamada & Comentário & Chapéu & \\
Índice & Opinião & Olho & \\
Cabeçalho & Reportagem & Tabela & \\
& Entrevista & Gráfico & \\
& Claquete & Citação & \\
\hline
\end{tabular}

Fonte: Bonini, 2001.

Este jornal escolar pode ser caracterizado como gênero porque apresenta alguns dos elementos acima. Um primeiro aspecto a ser considerado é a presença de itens de paginação. A inserção de números de página na publicação permite transformar uma coleção independente de textos e folhas em uma unidade caracterizada por um projeto de dizer.

Figura 2 - Exemplo de paginação do Jornal 803 Intensivo

Prefeitura de Tubarāo

Secretaria de Desenvolvimento Social

Rua Lauro Moller, 500. Centro.

Telefones: $\langle 48\rangle 3906-1036 / 3906-103\rangle$

E-mail: socisleptubaràoscgon br

Atendimento: das 13 às 19 horas.
Centro de Integração Empresa-Escola - CIEE Av. Marcolino M. Cabral, 1788, Centro.

Telefones: (48) $3626-8113 / 3626-8287$

E-mail: cicetubareoficiescorg.br 
Fonte: Edição n.1 do jornal 803 Intensivo publicada em julho de 2012, pelos alunos da turma autora do projeto.

Os gêneros que aparecem nessas edições ajudam a configurar sua organização textual e a concretizar sua definição como um hipergênero. Esses gêneros são característicos do jornal, isto é, aparecem em produtos relacionados ao jornalismo e, geralmente, em locais fixos, a fim de permitir, também, o reconhecimento do público consumidor. Além disso, essa tipificação, pela qual o gênero passou, faz com que o sujeito, ao pensar em produzir jornal, atribua a ele um aspecto visual recorrente em outros jornais, algo que auxilia no processo de constituição e estruturação do jornal. Um aspecto que permite configurar esta produção como gênero jornal é o cabeçalho:

\section{JORNAL 803 INTENSIVO \\ Jornal-piloto produzido pela Turma 803 Intensivo da Escola Célia Coelho Cruz. \\ Julho/2012.}

Figura 3 - Cabeçalho do Jornal 803 Intensivo

Fonte: Edição n. 1 do jornal 803 Intensivo publicada em iulho de 2012. pelos alunos da turma autora do projeto.

O cabeçalho costuma aparecer na capa, no topo da página e de maneira que o público consumidor possa percebê-lo imediatamente. O cabeçalho é constituído de informações sobre o jornal, como o título, a data da publicação, o número da edição e a marca de referência (o logotipo) da publicação. No caso do jornal escolar, informa quem esteve envolvido com a produção e traz a informação sobre a escola a que pertencem os produtores dos textos publicados. Neste, produzido pela turma 803 Intensivo, o cabeçalho faz referência ao nome da turma e se repete na segunda edição, conforme figura abaixo:

Figura 4 - Cabeçalho da segunda edição do Jornal 803 Intensivo.

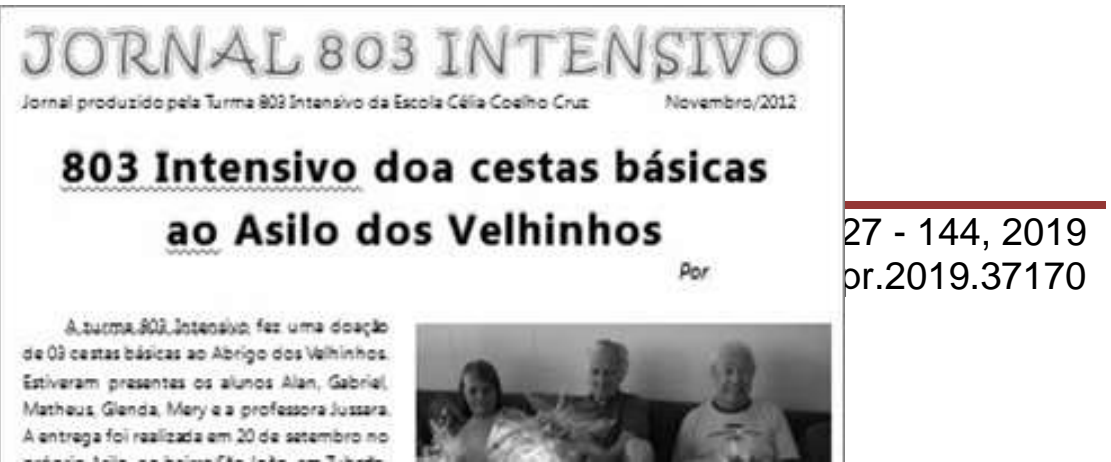


Fonte: Primeira página da edição n. 2 do jornal 803 Intensivo publicada, em novembro de 2012, pelos alunos da turma autora do projeto.

Outro gênero que aparece no hipergênero jornal, é o expediente. Presente nos jornais convencionais, o expediente é formado por um conjunto de informações que identificam o jornal, tais como: a listagem da equipe da redação (ao menos a direção, as chefias e as editorias), os dados de tiragem e de circulação, os endereços e telefones para contato sobre assinaturas e edições anteriores. No jornal escolar, por não ser comercializado (ao menos neste caso), não há informações como telefone de contato para assinaturas ou dados de tiragem. Nessas edições do jornal 803 Intensivo, o expediente também está presente, porém as informações que o constituem, limitam-se a identificar os alunos produtores ${ }^{3}$ dos textos e o professor responsável pela publicação. Nas duas edições, ele aparece conforme figuras 5 e 6 , a seguir:

Figura 5 - Expediente do Jornal 803 Intensivo

Expediente: Projeto de jomal escolar produzido pelos alunos da Turma 803 Intensivo

Professcra Resporsávet Vanessa W Lima.

Fonte: Edição n. 1 do jornal 803 Intensivo publicada em julho de 2012, pelos alunos da turma autora do projeto.

Na primeira edição, o expediente está localizado na página 4. Na segunda, o expediente pode ser encontrado logo na página 1, de acordo com figura 6 abaixo:

Figura 6 - Expediente da segunda edição do Jornal 803 Intensivo.

Expediente: Jornal escolar produzido pelos alunos

e , da turma 803 Intensivo, sob a coordenação da professora

Fonte: Edição n. 2 do jornal 803 Intensivo publicada em novembro de 2012, pelos alunos da turma autora do projeto.

${ }^{3}$ Os nomes dos estudantes foram removidos a fim de preservar suas identidades. 
Outros dois gêneros comuns ao jornal e que também aparecem neste jornal escolar são a notícia e a reportagem. A notícia tem, segundo Bonini (2008, p. 37), "o propósito de relatar um fato/acontecimento". A definição de reportagem, por sua vez, depende de se olhar para o que é mais característico: a reportagem enfoca assuntos e não eventos.

É possível encontrar nessas edições, alguns exemplos de notícia e de reportagem, mesmo que o ensino desses gêneros não tenha sido contemplado no projeto e, sobretudo, não tenham servido de referência para as produções textuais. A presença desses dois gêneros no jornal escolar é um dos motivos para que o jornal seja considerado um hipergênero.

Figura 7 - Exemplo de notícia publicada no Jornal Escolar 803 Intensivo

\section{Intensivo doa cestas básicas}

ao Asilo dos Velhinhos

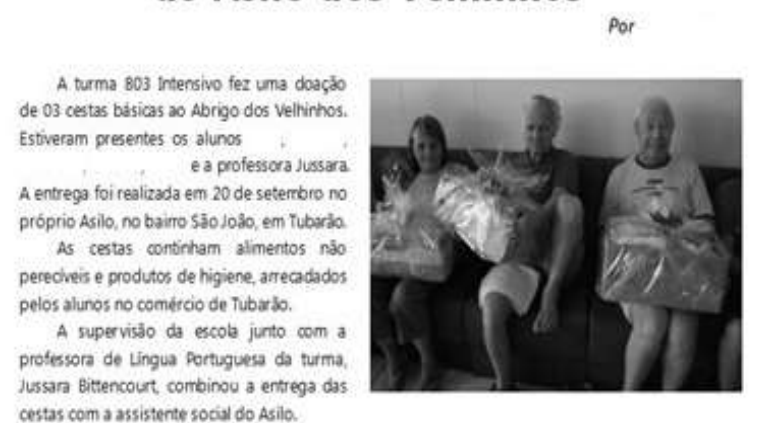

História - O Abrigo dos Velhinhos é o único asilo do municlpio de Tubardo, Foi fundado no dia 15 de setembro de 1962 e é manbido pelo Clube das Ladies (gripo de serhoras da cidade). Recebe tambem doaçbes de empresas da regibo e comuridade Vivem no asilo. atualmente 20 idosos.

0 abrigo recobe vistantes, dariamente. das 15 aेs 17 horas. Grupos maicres devem agendar visita com a assistente social Gislai ne. Mais informaçdes abavés do (48) 3628 . 0351 ou pessoalmente na Rua SSo Jabo. 1125 , bairro Sảo job3o, margem esquerda

Fonte: Edição n. 2 do jornal 803 Intensivo publicada em novembro de 2012, pelos alunos da turma autora do projeto.

Considerando que uma notícia é, em essência, o relato de um fato/acontecimento, este texto pode ser configurado como o relato de uma coleta e doação de cestas básicas que a turma produtora do jornal realizou no mesmo período da produção da edição. Entretanto, a motivação que levou a tal publicação pode não ter sido o interesse do público leitor pelo assunto. Talvez seja possível pensar que esse interesse pelo tema tenha vindo mais do público produtor, tendo em vista que são eles mesmos os autores da doação. Entretanto, como a questão central aqui é a presença de gêneros que justifiquem a conceituação do jornal como 
um hipergênero, a relevância da publicação não é algo a ser considerado no momento.

No que se refere à presença do gênero reportagem, nessas duas edições de jornal escolar podem ser encontrados alguns exemplos de reportagens didáticas. No entanto, antes mesmo de elencar alguns desses textos, é preciso destacar que as reportagens produzidas para o jornal 803 Intensivo não serviram como instrumento de ensino do gênero jornalístico reportagem. Conforme dito anteriormente, esta produção de jornal escolar não contemplou o ensino de gêneros jornalísticos. Mas, ainda assim, é possível descrever os textos publicados como semelhantes a reportagens didáticas, tendo em vista que as produções textuais publicadas buscam "explicar um assunto, situação problema ou serviço" (BONINI, 2008, p. 37). Nas figuras 8 e 9 , encontra-se as reportagens didáticas produzidas para as duas edições do Jornal 803 Intensivo:

Figura 8 - Exemplo de reportagem didática publicada no Jornal 803 Intensivo

\section{Trabalho na adolescência}

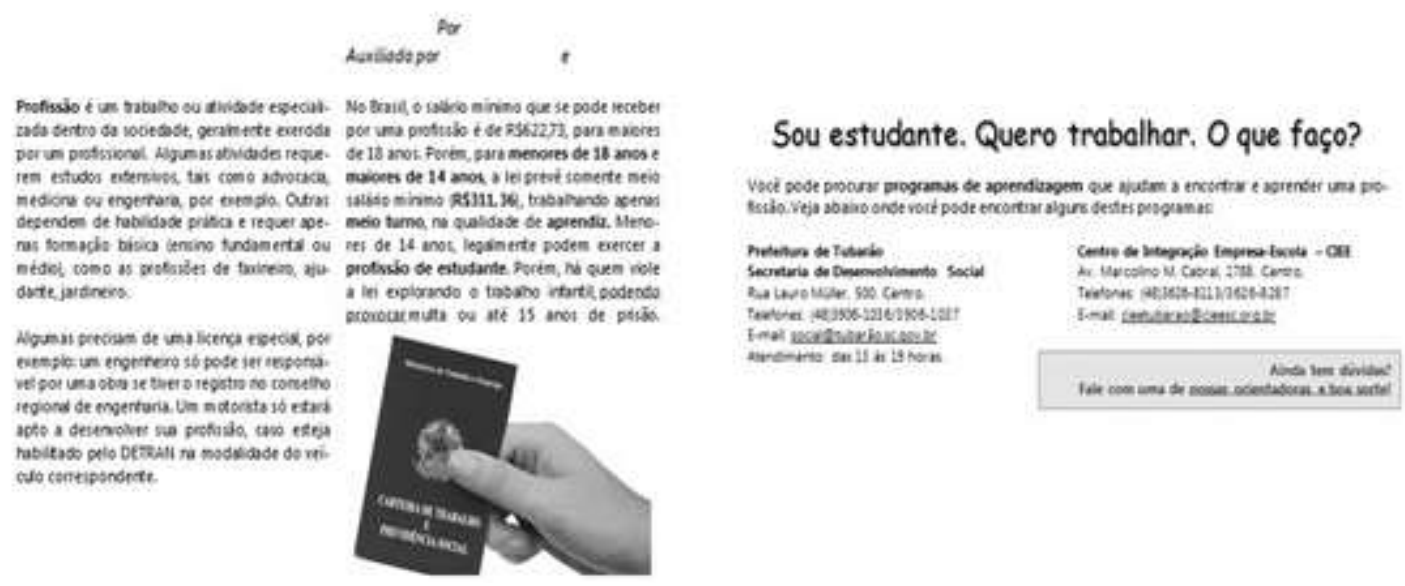

Fonte: Reportagem didática publicada na página 1 da edição n. 1 do Jornal 803 Intensivo publicada em julho de 2012, pelos alunos da turma autora do projeto. 
Figura 9 - Exemplo de reportagem didática publicada no Jornal 803 Intensivo

\section{Jogue futebol: faz bem à saúde}

7

ado mundo fala que a gente tem que fazer atividade fisica, mas nem sempre a gense tem dimheiro pra paga uma academia. Hoje vamos falar de uma stividade que pode zer de grace: o futebol. $O$ futebol é un dos esportes mais popu lares do mundo.

0 futebol tornou-se popular gracas a seu jeito de jogar; basta uma bola, equipes de joga dores $e$ as traves, para que, em qualquer es. paço cranças e adultos possam se divertit com o futebol. Na na, na escola, no clube, no campinho do bairro ou até mesmo no quintal de casa, desde cedo jovers de vários cantos do mundo aprendem a jogar bola.

- futebol pode ser jogado de varias maneiras: em quadras de saliso ou sukpo. em camoos naturas. Pra ogar futebol de area, salibo ou suiço você precisa apenas de 5 pessoas. para jogar futebol voce precisa fazer alguma atividade fisica como se alongar após a partida de futebol.
Por Os perigos do sedentarismo

Quando nio praticamos exercicios fisicos e deixamos o sedentarsmo vmar conta de nosso corpo, a capacidade de respiraclo pro. funda diminui eo coracho e a circulacio do sangue para tecidos e órgảos também déxa de funcionar adequadamente. Basta um pou: co de esforcy para ficz rapidamente cansado e sentir dificuldade até mesmo na erecucajo das tarefas diarias.

Mexa-sel

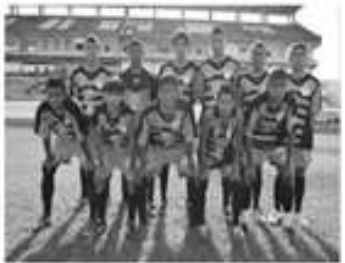

Os beneficios do futebol para o corpo

para termos saude precisamos praticar abyma atividade ffica. Mas nem sempre temos dinheiro ou tempo par irmos a uma academia. Voce sabia que existem atridades fisicas que slo gritis e bem ftces de praticar. 0 f

Primeiro, visite um módico e tapa um eame fisico com detahes para verificar possiveis problemas de savide.

Depos, com a ajuda de um profassional de educapio fsica, tạ uma avaliaçä partithando com ele seus cojebivos e necessida. des. A partir doso e que se pode definir o plano de exercícios adequado

Prascar esporte traz mutos beneficos à saide e o futebol nå fica atras. Outra wantagem de praticar este esporte é ficar com pernas de pratcat ete exporte e ficar wom pernas artese bontas, Alem dissa, o hatbol pode ajuar ra diminicaso de gordus locaitada.

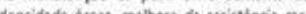
densida cosses, meihora dis resisténcia cardiovascular
E precso ter regularidade e se exercitar por 30 minutos peb menos tris vezes por se. mana $\mathrm{Em}$ astidides, como a musculacio. caso o teino seja dario, será preciso dinidir os grupos musculares para nso sobre carregar. Nä adianta dar o maximo em un dia, e nos proximos quatro dias nio se exercitar.

Fonte: Reportagem didática publicada na página 2 da edição n. 1 do Jornal 803 Intensivo publicada em julho de 2012, pelos alunos da turma autora do projeto.

Outro exemplo da presença de reportagem didática neste Jornal é demonstrado abaixo:

Figura 10 - Exemplo de reportagem didática publicada no Jornal 803 Intensivo 


\title{
A gravidez na adolescêncía
}

\author{
Por
}

$x$

adoleacheia 6 uma fass bastante problamitca na macria das vasas en razlo das descobertas das ideias opostas as dos pais a irmbes da foch maclo da identidade fasa na qual as converas anvolvam namoro brincxdeiras a asann. tod proibidor \& u ma fas do desanvolvimento que estd entra a inflecia a a fase adulta Witas alteracbes alo percebidas no sorpo humano. nos pensamsentos a nas atitudes dessas jovens

formacbo psicelogica a baja atostima. Por isso, o apoio da famillo 4 tlo importanta pois a famili a a a ba az que poderá propocionar compreanalo didlogo, seguranca afuto a axilio para qua tants os adoleacentas anvolvidos quanto a crianca oue foi garada al de sanvolva reutival Com o apoo da fam ia aborto a difculdades de amamentaclo thm seus riacos diminuidos Alteracbes na gestaSto envolem oiferentes alteracbes no corpo da jovam gravida a aintemas cemo daprasalo a mauthumor podam piorar ou mahoar

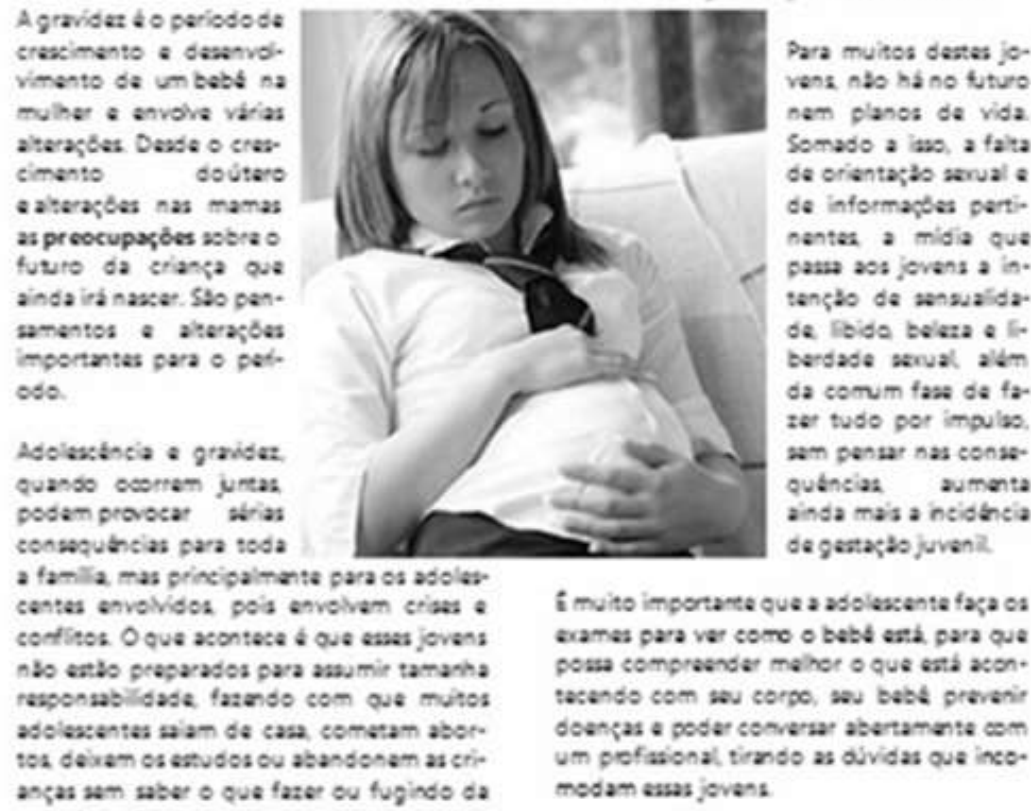
jatas ath saber o oue fazer ou funindo or pedpria realdada.

A gravidez presece pode cutar ralacionada a

Converse com elouím en que você confie!

Fonte: Reportagem didática publicada na página 3 da edição n. 1 do Jornal 803 Intensivo publicada em julho de 2012, pelos alunos da turma autora do projeto.

Os três exemplos de reportagem didática podem demonstrar a presença constante do gênero em questão nas duas edições, tendo em vista que os textos publicados seguem os mesmos padrões.

Os aspectos destacados acima (os gêneros cabeçalho, expediente, notícia, reportagem e o elemento paginação) são frequentemente relacionados ao jornal (BONINI, 2008) e podem ser também relacionados ao jornal escolar analisado aqui. Agrupados numa mesma publicação, eles auxiliam a constituir uma unidade maior, o hipergênero jornal escolar. Esses elementos contribuem para que o jornal assuma uma organização textual específica, uma organização comum à maioria dos jornais. 


\section{Análise crítica do jornal escolar}

Ao assumir o entendimento de jornal escolar como gênero e, tendo em vista que este último pode ser visto como "um conteúdo representacional dinâmico que corresponde a uma forma característica de um texto sob a forma de enunciado" apresenta-se os elementos que determinam o enunciado para a discussão, como forma de corroborar a definição de jornal como gênero. Esses elementos são, segundo Bakhtin (2011/1953, p. 275): a) "alternância dos sujeitos do discurso" e, b) a "conclusibilidade", que pode ser dividida em: "exauribilidade do objeto e do sentido", "projeto de discurso ou vontade de discurso do falante" e as "formas típicas composicionais e de gênero do acabamento".

Dessa forma, o jornal escolar caracterizado como enunciado, apresenta uma "alternância dos sujeitos do discurso", tendo em vista que o jornal escolar apresenta "um modo dixi que assinala a alternância de enunciados" e, tendo em vista que este jornal escolar possui uma periodização semestral, isso permite que o outro (a comunidade escolar, por exemplo) se manifeste em relação ao seu conteúdo.

Quanto à conclusibilidade do enunciado, referente à "exauribilidade do objeto e do sentido", este é um aspecto que tende a se mostrar mais abertamente no jornal escolar. Se o jornal escolar é tomado como um enunciado produzido por uma "equipe que expressa todo o conteúdo que pode expressar naquela edição", é possível pensar na exauribilidade do objeto e do sentido, tendo em vista que é incomum que conteúdos sejam retomados em outras edições e porque, assim, o público consumidor do gênero jornal escolar pode manifestar sua atitude responsiva ativa e, assim, produzir reações que podem levar a novas produções ou à paralisação das publicações.

No que se refere ao "projeto de discurso do falante" no jornal escolar, neste caso, não se pode identificar um intuito através do enunciado, ou seja, dessas edições de jornal escolar. Apesar de ser uma característica esperada de um jornal, este jornal não apresenta uma linha editorial. Ao considerar que não há uma linha editorial clara e definida, seria possível caracterizar esse jornal como uma coleção de textos, entretanto, essa ausência de linha editorial não significa a ausência de um projeto de dizer. Talvez seja possível dizer que o projeto de dizer desse enunciado 
esteja relacionado muito mais à tentativa de fornecer alguma visibilidade à turma e a sua produção, que propriamente à função de definir um tema e discuti-lo frente à comunidade escolar.

Quanto às "formas típicas composicionais e de gênero do acabamento" no enunciado em questão, o que se espera de um jornal escolar é que este apresente elementos que facilitem seu reconhecimento como tal. Esses elementos podem ser uma linha editorial (que representa o projeto de dizer da publicação), ou uma divisão por seções que organizam os textos (como esporte, polícia, comunidade), ou ainda, uma seção de carta do leitor. Alguns elementos podem ser encontrados nos jornais analisados, como o expediente, o cabeçalho, a notícia ou a reportagem. Porém, é clara a ausência de seções, cadernos ou ainda, de chamadas que direcionem a atenção do leitor para o interior da publicação.

A ausência desses elementos evidencia que este jornal escolar é diferente do que se idealiza para uma produção desse tipo, mas, ainda assim, essa ausência não invalida a caracterização deste jornal escolar como um gênero constituído por outros gêneros. Itens como o cabeçalho, a paginação, o expediente e a presença de notícias e reportagens são itens suficientes para caracterizá-lo como tal. Além disso, se há um projeto de dizer no enunciado, há um gênero sendo produzido e criando espaço para a circulação de outros gêneros.

Nesse sentido, se nestes jornais escolares existem aspectos capazes de propiciar sua configuração como gênero, também há aspectos ausentes sobre os quais é preciso refletir. Os motivos de essas duas edições de jornal escolar não se assemelharem à maioria das produções de jornal escolar estão relacionados ao contexto que envolveu a produção. Naquele momento, por influência das práticas sociais, essa foi a possibilidade de produção.

A produção deste jornal escolar esteve envolvida por práticas sociais que circundam não apenas a realidade local desses estudantes e suas histórias, mas também suas crenças (a de que não sabiam fazer, por exemplo), seus valores (influenciados por uma visão de mundo limitada a suas experiências com este mesmo mundo) e essas influências se mostraram em sua "deficiente" produção de texto.

Quanto à ausência de uma linha editorial, por mais que um dos pontos pensados no projeto inicial fosse um trabalho com um jornal escolar que 
apresentasse uma linha editorial definida, com o andamento do projeto e a falta de engajamento dos estudantes ficou clara a dificuldade de definir uma linha editorial, impedindo que o gênero sofresse uma amarração, um acabamento idealizado para uma produção escolar com esta. A produção de textos não se configurou como uma produção de gêneros específicos para o jornal escolar, como tomar a produção de notícias ou de reportagens para as edições como um objetivo do projeto. Isso se deve também à visão que a própria turma tinha sobre si. Essa visão também influenciou na produção do gênero, fazendo com que o projeto passasse por modificações.

Este jornal é diferente do que se espera de um jornal escolar por conta, também, da ausência do trabalho em grupo e da dificuldade em se formar equipes produtoras de textos. O trabalho pautado na produção individual influenciou no projeto de dizer do enunciado, haja vista que, por essa característica, o jornal poderia até ser caracterizado como uma coleção de textos. A prática de trabalhar individualmente é evidenciada nos textos produzidos por apenas um autor, quando uma equipe editorial poderia se responsabilizar pela produção do jornal como um todo.

Assim, o gênero jornal escolar sofreu influências oriundas tanto de práticas sociais externas, no que se refere às falhas da autora deste trabalho e às dificuldades apresentadas pelos estudantes de modo geral, quanto internas, quando o gênero não mostra claramente um projeto de dizer. A ausência de elementos que concretizam o jornal escolar como gênero, por exemplo, também é uma consequência da influência dessas práticas sociais. É possível caracterizá-lo como gênero porque outros gêneros estão presentes na produção, no entanto gêneros essenciais, como o editorial, por exemplo, fazem falta no momento de estabelecer um projeto de dizer para o enunciado.

\section{Considerações finais}

A produção textual em sala de aula deve se configurar como uma forma de agir sobre o mundo em que se vive e permitir que o estudante saia da posição de receptividade que lhe foi imposta e consiga agir como protagonista em seu próprio aprendizado, levando-o a agir também dessa forma no mundo em que vive. 
As influências pelas quais um gênero passa estão para além do expresso textualmente, isso porque o gênero está imerso em práticas sociais que lhe são inerentes e que determinam sua forma, seu conteúdo, a maneira como os sujeitos o (re)produzem e o compreendem. Essa relação dialógica é um fator constitutivo do gênero, evidenciando que um gênero está sempre conectado a outro, que uma prática discursiva está sempre ligada a outra, interferindo-se e influenciando-se mutuamente.

O objetivo desse trabalho era o de analisar, do ponto de vista da Análise Crítica de Gênero, a relação entre gênero e prática social em jornal escolar produzido por alunos de uma turma de correção de fluxo dos anos finais do ensino fundamental de uma escola pública estadual do município de Tubarão, SC. Essa produção, caracterizada como jornal escolar, apresenta características diferentes do esperado para uma publicação do tipo, porque as práticas sociais nas quais a equipe produtora estava envolvida influenciaram na constituição do gênero jornal escolar. Dessa forma, por mais que uma proposta de ensino de gêneros seja cuidadosamente planejada, o momento da produção genérica será influenciado pela prática social e esta, por sua vez, influenciará o projeto como um todo.

Ao entrar em sala de aula, o professor deve estar atento não só àquilo que se realiza nas aulas, mas às influências extraescolares e sociais como um todo. $O$ gênero é um exemplo de como a estrutura e a prática social influenciam indivíduos, mesmo produções textuais escolares.

\section{Referências bibliográficas}

BAKHTIN, M. M. Estética da criação verbal. Tradução: Paulo Bezerra. São Paulo: Martins Fontes, 2011/1953.

BAZERMAN, C. Gêneros textuais, tipificação e interação. Tradução: Judith Chambliss Hoffnagel. São Paulo: Cortez, 2006.

BONINI, A. Em busca de um modelo integrado para os gêneros do jornal. In: CAVALCANTE, M. M.; BRITO, M. A. P. (Orgs.). Gêneros Textuais e Referenciação. Fortaleza: Grupo Protexto, 2001. CD-ROM.

As relações constitutivas entre o jornal e seus gêneros: relato das pesquisas do Projeto Gêneros do Jornal. In: BRAGA, S. et al (Org.). Ciências da linguagem: avaliando o percurso, abrindo caminhos. Blumenau: Nova Letra, 2008. 
p. 21-45.

. Mídia, suporte e hipergênero: os gêneros textuais e suas relações. Revista Brasileira de Linguística Aplicada, Belo Horizonte, v. 11, n. 3, p. 679-704, 2011.

FAIRCLOUGH, N. Discurso e mudança social. Tradução: Izabel Magalhães. Brasília: UnB, 2008/1992.

Analysing discourse: textual analysis for social research. London: Routledge, 2003.

LIMA, V. W. A prática social no jornal escolar: estudo do ponto de vista da análise crítica de gênero. 2014. 136 f. Tese (Doutorado em Ciências da Linguagem) Universidade do Sul de Santa Catarina, Tubarão, Santa Catarina, 2014.

SWALES, J. Genre analysis: English in academic and research settings. New York: Cambridge University Press, 1990.

\section{Sobre a autora}

Vanessa Wendhausen Lima

Doutora e Mestre em Ciências da Linguagem (UNISUL). Licenciada em Letras e Bacharel em Jornalismo (UNISUL). Atualmente é professora dos cursos de Design, Jornalismo e Publicidade e Propaganda da Faculdade Satc, de Criciúma/SC. 